\title{
Comunicación

\section{Ciberpolítica. Las nuevas formas de acción y comunicación políticas}

RAFAEL CABALLERO ÁlVAREZ1

Un tema de evidente actualidad es el desarrollo de la política en los medios electrónicos; una tendencia que crece día con día, aunque todavía existan quizá más preguntas que respuestas acerca de cómo se ha venido dando este fenómeno. Al respecto, Ramón Cotarelo, prestigiado catedrático español, en colaboración con 11 colegas más, colocan sobre la palestra el tema y hacen una aportación notable a su discusión académica. El origen de ello estriba en las Primeras Jornadas Españolas de Ciberpolítica convocadas por el Departamento de Ciencia Polítia Distancia de España -dirigido por Cotarelo-, en colaboración con el Colegio de Licenciados y Doctores en Ciencias Políticas y Sociología, así como la Fundación Ortega/Marañón.

Cotarelo, R. (Ed.). (2013). Ciberpolitica. Las nuevas formas de acción y comunicación políticas. Valencia, España: Tirant Humanidades, $328 \mathrm{pp}$.

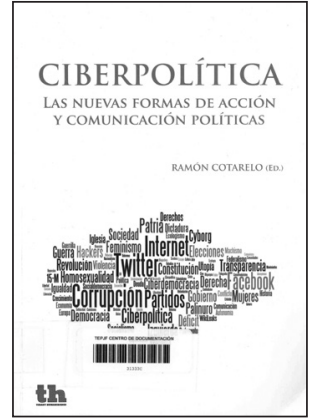

1 Centro de Capacitación Judicial Electoral, Tribunal Electoral del Poder Judicial de la Federación, México.

Correos electrónicos: rafael.caballero@te.gob.mx y r_caballero_a@hotmail.com 
Las investigaciones de los autores contienen un componente empírico muy marcado respecto del caso de España, aunque la discusión de fondo es de carácter universal, sobre todo considerando que los medios digitales trascienden fronteras políticas, geográficas e incluso culturales y lingüísticas. Tal discusión se organiza en la obra conforme a tres secciones temáticas, a saber: gobierno electrónico; comunicación política y redes sociales; y movilización política y redes sociales.

El hecho de que las redes sociales se constituyan como eje temático de una buena parte del libro resulta revelador en el sentido de que la ciberpolítica no es una actividad exclusiva de los profesionales de la política -es decir, de los políticos- sino que colabora con la reivindicación de la clásica noción aristotélica del hombre como animal político, en la medida en que posibilita y alienta nuevas y más amplias formas de participación ciudadana. Esto lo advierte Cotarelo desde el prólogo, cuando afirma que la ciberpolítica:

Es la existencia de una nueva ágora digital unitaria pero tremendamente diferenciada pues en ella participan en un clima de igualdad los órganos de gobierno del país, los ciudadanos con sus blogs y a través de sus redes sociales, las empresas, los sindicatos, etc. (p. 15).

La ciberpolítica se refiere entonces a nuevas formas de interacción entre el gobierno y los ciudadanos, entre éstos y los partidos políticos, entre las empresas y los órganos legislativos, entre ciudadanos de un régimen político y entre ciudadanos del mundo. La actividad política que se suscita en el ciberesepacio permite que las instituciones, entidades y personas se interrelacionen más estrechamente sin importar la distancia material que exista de unos a otros. En el caso del gobierno digital, por ejemplo, actualmente es fácil advertir la incorporación de sistemas electrónicos para facilitar trámites a la ciudadanía o para favorecer el escrutinio sobre el desempeño de la administración pública. Los recursos tecnológicos, de hecho, han resultado de enorme utilidad en los esfuerzos de transparencia y rendición de cuentas en distintos países durante los últimos años.

Por otra parte, incluso cuando el también llamado gobierno electrónico tiene muchas bondades, suele tener carencias todavía lejos de 
superarse. Algunas de ellas son identificadas por Salvador Parrado en su colaboración a esta obra, entre las que se encuentra el hecho de que las administraciones públicas no atinen a identificar la información más pertinente que ponen al alcance de los usuarios y que no exista coordinación entre las distintas agencias gubernamentales que pudieran estar vinculadas por la naturaleza de sus funciones (interoperabilidad). Esta debilidad de interconexión, que puede ser incluso típica de ciertos sistemas de administración pública tradicionales, pareciera no solo estar lejos de desaparecer, sino que da la impresión de ser susceptible de adaptarse a la era digital. Sin embargo, las cuentas oficiales de Twitter o Facebook de las dependencias públicas -siempre y cuando tengan una administración eficiente- colaboran un poco a combatir esta situación a partir de que dan al usuario la oportunidad de interactuar de algún modo con la dependencia en tiempo real o al menos de forma más expedita.

Adicionalmente, si bien a los modelos de gobierno digital se les ha denominado también de gobierno abierto, este último concepto plantea retos que trascienden la sola utilización de medios electrónicos en la gestión pública, comenzando por la voluntad política para comprometerse con una auténtica transparencia. Algunos otros elementos a considerar son planteados por Ignacio Criado y se relacionan con propiciar una mayor interacción con los usuarios, e incluso, con posibilitar su participación en la gestión pública mediante redes sociales como Facebook o Twitter, o bien mediante herramientas como wikis o blogs. De hecho, Josep Maria Reniu Vilamala expone un caso empírico muy ilustrativo sobre una consulta realizada a la ciudadanía respecto de la pertinencia de modificar una de las avenidas principales de la ciudad de Barcelona, en la que se compaginaron mecanismos tradicionales y tecnologías de la información en distintas fases, particularmente mediante la habilitación de un sitio web denominado: "i.de.a. Diagonal" (cuyo significado era: imagina, decide y aplica), el cual no solo servía como repositorio de información, sino que permitía el involucramiento ciudadano en el proyecto. Otra experiencia empírica es abordada por Mónica López Viso y Mario Ortiz García, en torno al esfuerzo realizado por la administración municipal de la ciudad de Ourense en el año 2012, que bien podría considerarse como una iniciativa modelo en materia de gobierno digital - o como lo definen los autores, de cibergobernanza 
administrativa- y que incluso le contó para obtener un reconocimiento de la empresa Google como Ciudad Digital.

Los capítulos intermedios del libro se ciernen sobre el tema de los medios de comunicación tradicionales versus las redes sociales. En primer lugar, Palmira Chavero hace un comparativo acerca del tratamiento que se le dio a tres fenómenos políticos suscitados en años recientes en la nación española, tanto en prensa escrita como en redes sociales, principalmente Twitter, a saber: la huelga general de septiembre de 2010, el movimiento de los indignados de $2011(15 \mathrm{M})$ y las campañas de las elecciones generales del mismo año $(20 \mathrm{~N})$. Una comparación similar sobre este último tema, aunque de manera más específica, es abordada por Antón R. Castromil, quien igualmente destaca las virtudes de Twitter como un instrumento dinámico para el intercambio de información, lo que lo hace -dice-idóneo para la discusión, la confrontación de ideas, el debate, el activismo e incluso para el "gamberrismo, la crítica ácida, el insulto y la difamación" (p. 157). No obstante, advierte una desventaja en la fugacidad de la información, en función de que los mensajes de Twitter son perecederos.

Continuando con este tema, aunque Montse Fernández Crespo da un título a su participación escrita en este libro sobre medir la eficacia de las cibercampañas, su texto se enfoca más a identificar algunos elementos que permiten pulsar el desarrollo de las campañas y las tendencias del voto en la red. Por su parte, Juan Pizarro Miranda aborda tres cuestiones fundamentales sobre la información disponible en Internet: quién la genera (creadores de contenidos), cómo se organiza (de qué forma se distribuye y filtra) y cómo se difunde (quiénes la consumen y cómo la comparten). El capítulo que cierra este apartado es de la autoría de Olga Gil, quien desarrolla el concepto de acción colectiva a la luz del avance de las nuevas tecnologías y a partir de ello expone un abanico de posibilidades en materia de involucramiento e innovación para las personas, empresas y gobiernos, que lo mismo pasan por el activismo político que por la potencialidad comercial y el cuidado de la naturaleza.

El editor del libro también tiene una destacada participación con un artículo que contiene una robusta reflexión teórica sobre el papel histórico -historicista tal vez sea una expresión más precisa- de los 
partidos políticos y de los medios de comunicación -incluido, desde su aparición, Internet-, así como de los puntos de encuentro entre ambos. En esta discusión planteada por Cotarelo, los conceptos de acción colectiva y movimientos de multitudes (que no de masas) ocupan un lugar preponderante.

Por su parte, Óscar G. Luengo habla sobre el papel de los medios de comunicación y su capacidad de influencia en la configuración de una cultura política determinada, particularmente con base en la experiencia estadounidense a partir de los años sesenta. Ello sirve de introducción para reflexionar en torno a Internet como un medio de nueva generación -aunque reconoce la existencia de un debate abierto sobre si a Internet se le puede considerar en efecto un medio de comunicación- y para compartir datos estadísticos muy significativos, producto de las investigaciones del autor acerca de los cruces que existen entre los niveles de activismo político y los de consumo de Internet en varios países de Europa con distintos grados de democratización. Finalmente, María Ángeles Rubio Gil hace un análisis con cierto matiz etario, al enfocarse en el tema de la participación política de los jóvenes tomando como referencia la llamada Spanish Revolution -anglicismo para referirse al $15 \mathrm{M}$, incluido el hashtag- pero principalmente con base en sus propias investigaciones sobre la utilización que dan los jóvenes españoles a Internet y las redes sociales.

En suma, se trata de una obra con gran vigencia que arroja luces respecto de las oportunidades que brinda el mundo globalizado e interconectado tecnológicamente, así como los dilemas que representa. Ciertamente las experiencias concretas estudiadas por los autores parecieran trazar un escenario bastante halagüeño, aunque habría que reconocer -como lo hacen prácticamente todos ellos-que existen infinidad de variables que determinan la forma en que se suscita la ciberpolítica en un país o en otro. Para el caso de México, y de varios países de América Latina, habría que comenzar por cerrar la brecha digital y combatir esta variante de la desigualdad que mantiene a buena parte de la población desconectada del mundo. En ese sentido, la interconectividad universal todavía sigue siendo un reto a vencer; aun así, el poder de las redes sociales, por ejemplo, ya ha dejado su patente en la convocatoria a manifestaciones públicas o en la denuncia ciudadana que ha 
llevado al cese de funcionarios. Considerando que la democracia mexicana ha avanzado a pasos muy lentos hasta llegar al punto en que hoy se encuentra, quizás el desarrollo de la ciberpolítica también sea muy acompasado. La ventaja es que México ya pertenece al ciberespacio ... y aunque sea por inercia no podrá rezagarse. 